\title{
Local Immune Response in Skin of Generalized Vitiligo Patients
}

\section{Destruction of Melanocytes is Associated with the Prominent Presence of $\mathrm{CLA}^{+} \mathrm{T}$ Cells at the Perilesional Site}

\author{
René van den Wijngaard, Anna Wankowicz-Kalinska, Caroline Le Poole, \\ Bert Tigges, Wiete Westerhof, and Pranab Das \\ Departments of Pathology (RVDW, AW-K, BT, PD) and Dermatology (RVDW, AW-K, WW, PD), Academic Medical \\ Center, Amsterdam University, and Dutch Institute for Pigmentary Disorders (WW), Amsterdam, The Netherlands; \\ and Skin Cancer Laboratories (CLP), Loyola University Medical Center, Maywood, Illinois
}

\begin{abstract}
SUMMARY: In situ immune infiltrates in lesional, perilesional, and nonlesional skin biopsies from patients with vitiligo were analyzed by immunohistochemistry and compared with immune infiltrates found in the skin of normal healthy donors and relevant disease controls. An increased influx of activated skin-homing T cells and macrophages were seen in the perilesional biopsies. The overall percentages of cutaneous leukocyte-associated antigen-positive (CLA $\left.{ }^{+}\right) \mathrm{T}$ cells were similar to those found in normal healthy donors. This is compatible with the similar expression of E-selectin. Most strikingly, however, the $\mathrm{CLA}^{+} \mathrm{T}_{\text {cells }}$ in perilesional skin were mainly clustered in the vicinity of disappearing melanocytes, and $60 \%$ to $66 \%$ of these interacting $T$ cells expressed perforin and granzyme-B. The perforin ${ }^{+} /$granzyme- $\mathrm{B}^{+}$cells were not seen in locations different from that of disappearing melanocytes. Interestingly, the majority of the infiltrating T cells were HLA-DR/CD8 ${ }^{+}$. Another hallmark of the present study is the focal expression of intercellular adhesion molecule (ICAM)-1 and HLA-DR in the epidermis at the site of interaction between the immune infiltrates and the disappearing melanocytes. The data presented in this study are consistent with a major role for skin-homing T cells in the death of melanocytes seen in vitiligo. (Lab Invest 2000, 80:1299-1309).
\end{abstract}

V itiligo is a cutaneous pigmentary disorder that affects approximately $1 \%$ of the world population (Lerner, 1971). It is characterized by milk-white macules of the skin and complete disappearance of melanocytes at the lesional site (Le Poole et al, 1993b). The etiology of melanocyte destruction in vitiligo remains largely unknown. The causal mechanism may vary for different patients (Kovacs, 1998; Norris et al, 1994). However, an autoimmune mechanism has been proposed as an underlying cause of vitiligo. This hypothesis was based on the observation that several autoimmune diseases are associated with vitiligo. Additionally, increased autoantibody titers against melanocytic antigens have been reported (Harning et al, 1991) and elevated serum levels of soluble interleukin (IL)-2-receptor that correlate with disease activity have also been reported (Honda et al, 1997). The latter parameter, observed in various infectious and

Received April 24, 2000.

This investigation was carried out under project GNK/PA/ODP1O and GNK/DE/ODP9 of the van Loghem Immunology Institute, Academic Medical Center, University of Amsterdam, Amsterdam, The Netherlands, with maintenance support for RvdW, $A W-K$, and CleP from Stiefel Laboratories, Maidenhead, United Kingdom.

Address reprint requests to: Dr. P. K. Das, Department of Pathology (Room L-2-258), Meibergdreef9, 1105 AZ, Amsterdam, The Netherlands. Fax: $31206960389 ;$ E-mail: P.K.Das@AMC.UVA.NL autoimmune diseases, is particularly related to the activation of immunocompetent cells (Keystone et al, 1988; Wolf and Brelsford, 1988).

The autoimmune hypothesis gains further support from immunotherapy studies of melanoma patients (Rosenberg, 1997). Twenty-six percent of melanoma patients responding to IL-2-based immunotherapy developed vitiligo. This was in marked contrast to nonresponding melanoma patients and to renal cell carcinoma patients where no vitiligo cases were seen. These findings suggest that antimelanotic $T$ cells responsible for melanoma regression may also be linked to the destruction of normal melanocytes as seen in vitiligo and halo nevi (Zeff et al, 1997). Indeed, it was clearly demonstrated that cytotoxic $T$ cells (CTL) generated from melanoma tissue also recognize differentiation antigens expressed by normal melanocytes (Anichini et al, 1993). Melan-A is one of the melanocyte-specific differentiation antigens often recognized by CTL in melanoma (Coulie et al, 1994). In this respect, it is relevant that a high frequency of skin-homing, Melan-A-specific, CD8 ${ }^{+}$T cells can be detected in peripheral blood of vitiligo patients (Ogg et al, 1998). Recently, it was emphasized that some of the melanoma-specific CTL that recognize melanocytic antigens also express the cutaneous leukocyteassociated antigen (CLA) (Dunbar et al, 1999), which 
is associated with homing to skin (Picker et al, 1990). Thus, the relation between melanoma therapy and vitiligo (Rosenberg, 1997) is not surprising.

Despite this evidence, the in situ data on the role of infiltrating immunocompetent cells in generalized vitiligenous lesions are limited (Abdel-Naser et al, 1994; Badri et al, 1993). We have previously reported that in inflammatory vitiligo, a rare type of depigmentary disease, skin infiltrates of $T$ cells and macrophages around the perilesional (PL) site parallel the development of the lesions in a centrifugal manner (Le Poole et al, 1996). Although expression of CLA was evaluated in two studies, Badri et al (1993) and Le Poole et al (1996), the importance of $\mathrm{CLA}^{+} \mathrm{T}$ cell subsets in relation to melanocyte destruction was not explicitly demonstrated by double-label immunohistochemistry. Subsequently, despite these reports, the extent to which local immune response is associated with the development of vitiligo is still debated (Berd et al, 1996), due to the lack of appropriate in vivo studies on the immunopathology of generalized vitiligo.

This prompted us to investigate the in situ immune infiltrates in the nonlesional (NL), PL, and lesional (L) skin of generalized vitiligo patients. In the present study, selected biopsy materials were used for phenotypic characterization of immunocompetent cells by single- and double-label immunohistochemistry. Our results clearly demonstrate the in situ involvement of $\mathrm{CLA}^{+} / \mathrm{CD}^{+} \mathrm{T}$ cells in the destruction of melanocytes in generalized vitiligo.

\section{Results}

\section{Melanocytes}

Similar melanocyte distribution patterns were found in normal control (NC) and NL vitiligo skin, whereas melanocytes were absent from the lesional part of the PL epidermis (Fig. 1A). At the true border of the $\mathrm{PL}$ site, remnants of disappearing melanocytes could be seen; these melanocyte fragments were not observed in NL skin. Importantly, the observation of melanocyte degeneration in PL skin confirms our earlier findings obtained by confocal laser scanning microscopy (Le Poole et al, 1993b). The use of this technique ruled out the possibility that melano- cyte fragmentation is observed because dendritic processes of a melanocyte were in another field of view that was masking the entire cell body. L skin of all patients was totally depleted of NKI-Betebpositive melanocytes.

Double-label immunohistochemistry revealed that $30 \%$ of melanocytes (median value) in PL skin sections of the vitiligo patients expressed HLA-DR molecules. Double-immunoreactive melanocytes were particularly seen in parallel with cellular infiltrates. A higher percentage of HLA-DR and melanocyte-specific antibody, NKI-beteb, doubleimmunoreactive cells was observed in PL sections when a relatively low number of remaining melanocytes was present (see example in Fig. 2A). In NL skin, these double-immunoreactive cells (8\%) were detected in only one patient, whereas NC were always negative for double-immunoreactive cells. In this context, in other disease control specimens such as psoriasis and contact dermatitis, a low percentage of $\mathrm{HLA}^{-\mathrm{DR}^{+}}$melanocytes are occasionally seen (data not shown). Further, melanocytes in all of the investigated samples expressed the CD68 antigen with an intensity comparable to that of dermal macrophages (see "Macrophages"). An example of NKI-beteb/CD68 double-label immunoreactivity is shown in Figure 2B.

\section{T Cells}

An example of the distribution pattern of $\mathrm{CD}^{+} \mathrm{T}$ cells in $\mathrm{PL}$ vitiligo skin is presented in Figure $1 \mathrm{~B}$. $\mathrm{T}$ cells were focally present in the epidermal/papillary area and were mainly located around the basal epidermal layer. In the reticular dermis, both perivascularly located and scattered $\mathrm{CD}^{+}{ }^{+} \mathrm{T}$ cells were observed. In Table 1, CD4 to CD8 ratios are shown. $\mathrm{CD}^{+} \mathrm{T}$ cells composed the majority of the $T$ cell infiltrates in generalized vitiligo skin.

Total numbers of infiltrating $\mathrm{CD}^{+} \mathrm{T}$ cells are given in Figure 3. Despite marked donor-to-donor variation, the highest numbers of $\mathrm{CD}^{+}{ }^{+}$cells were found in the PL area. In the dermal compartment and in the epidermis/papillary dermis of PL skin, where the injured melanocytes are seen, the number of $\mathrm{CD}^{+} \mathrm{T}$ cells was significantly higher ( $p<0.005$ versus NC skin).
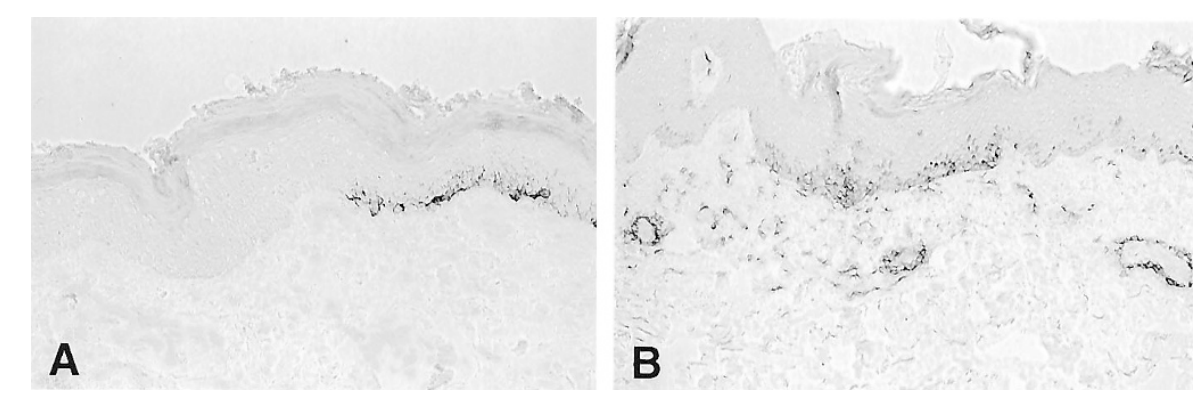

\section{Figure 1.}

A, Immunohistochemistry with the melanocyte-specific antibody NKI-beteb shows a partial absence of melanocytes from perilesional (PL) epidermis. B, CD3-immunoreactive T cells in PL skin. Original magnifications: $A, \times 66 ; B, \times 50$. 


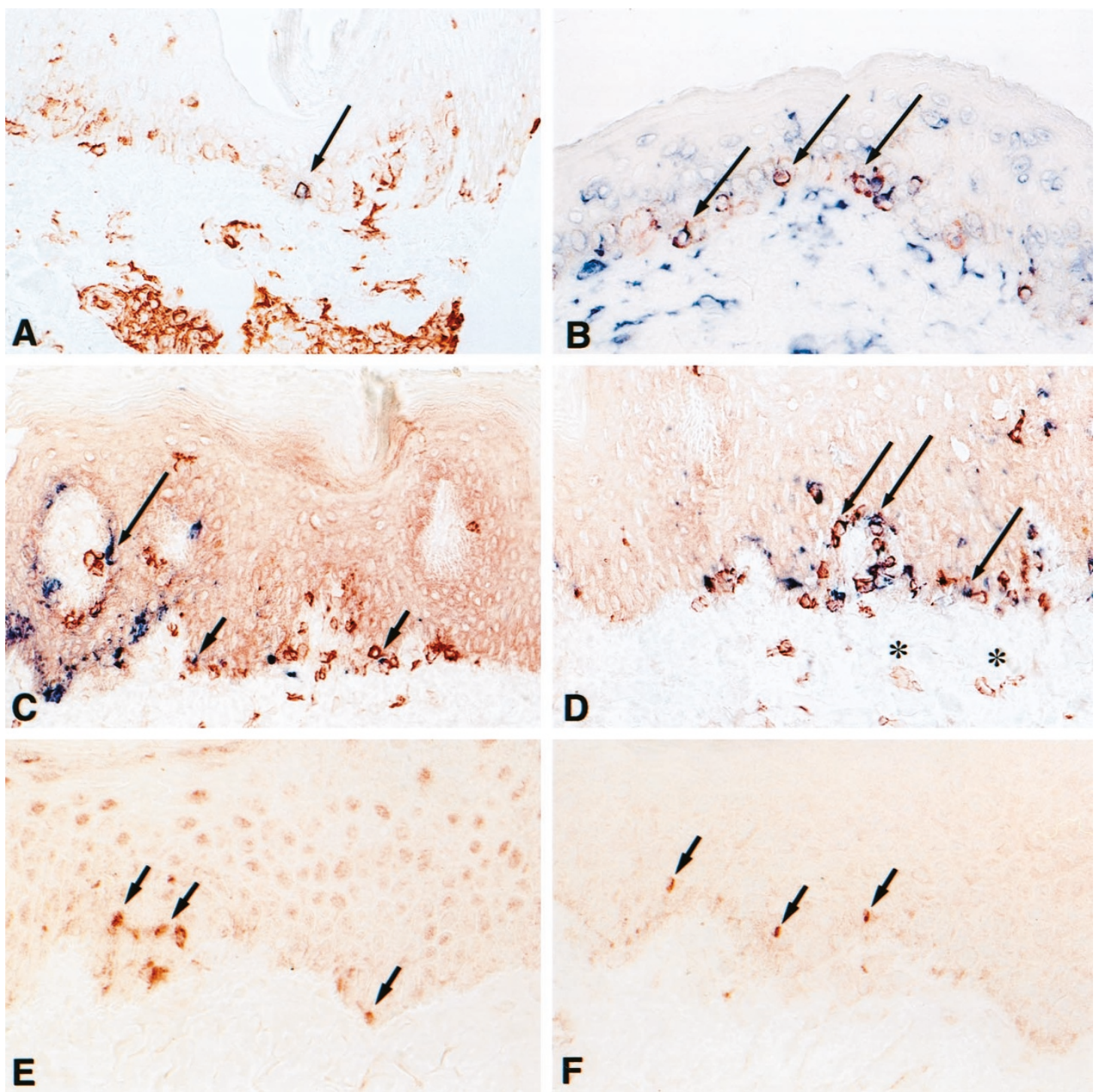

\section{Figure 2.}

A, NKI-beteb (blue)/HLA-DR (red) double-label immunoreactivity showing HLA-DR immunoreactivity of one remaining melanocyte (arrow) in PL skin. B, NKI-beteb (red)/CD68 (blue) double-label immunoreactivity of normal control (NC) skin showing CD68 ${ }^{+}$melanocytes (arrows). C to F, Serial sections of PL vitiligo skin. C, NKI-beteb (blue)/CD8 (red) double-label immunoreactivity; long arrow, CD8 ${ }^{+} \mathrm{T}$ cell apposed to melanocyte; short arrows, CD8 ${ }^{+} \mathrm{T}_{\text {cells }}$ apposed to melanocytic remnants. D, CD3 (red)/CLA (blue) double-label immunoreactivity showing a cluster of double-immunoreactive T cells (arrows) at the epidermal/dermal junction and CD3 single-immunoreactive cells in the dermal compartment (asterisks). Granzyme-B (E) and perforin (F) immunoreactivity in cells at the PL epidermal/dermal junction. Original magnifications: $\mathrm{A}$ and $\mathrm{C}, \times 132 ; \mathrm{B}, \times 100$; $\mathrm{D}$ to $\mathrm{F}, \times 160$.

Table 1. CD4/CD8 Ratios

\begin{tabular}{lcccc}
\hline & Nonlesional & Perilesional & Lesional & Normal Control \\
\hline Epidermis and Papillary Dermis & $0.4( \pm 0.3)$ & $0.4( \pm 0.3)$ & $0.6( \pm 0.9)$ & $1.1( \pm 0.8)$ \\
Reticular Dermis & $0.3( \pm 0.2)$ & $0.5( \pm 0.4)$ & $0.4( \pm 0.3)$ & $1.5( \pm 0.3)$ \\
\hline
\end{tabular}

CD4/CD8 ratios (mean $\pm \mathrm{SD})$ in generalized vitiligo $(n=7)$ and normal control skin $(n=3)$ as determined from CD3/CD8 immunohistochemical double stainings

$\mathrm{CD}^{+} \mathrm{T}$ cells apposed to remaining PL melanocytes and melanocytic remnants were clearly seen with NKI-beteb/CD8 double-label immunohistochemistry, an example of which is shown in Figure 2C. These T cell/melanocyte interactions were also observed in psoriasis and contact dermatitis skin sections but without degeneration of melanocytes (not shown).
The number of infiltrating $\mathrm{T}$ cells was elevated in $\mathrm{PL}$ vitiligo skin. However, the percentage of $\mathrm{CLA}^{+} \mathrm{T}$ cells was not increased and was comparable to that observed in NC and contact dermatitis skin $(40 \%$ to $60 \%$ ). On the other hand, $80 \%$ of the infiltrating $T$ cells in psoriasis were $\mathrm{CLA}^{+}$. Serial sections showed that, in vitiligo $\mathrm{PL}$ skin, $\mathrm{CLA}{ }^{+} \mathrm{T}$ cells were primarily clus- 


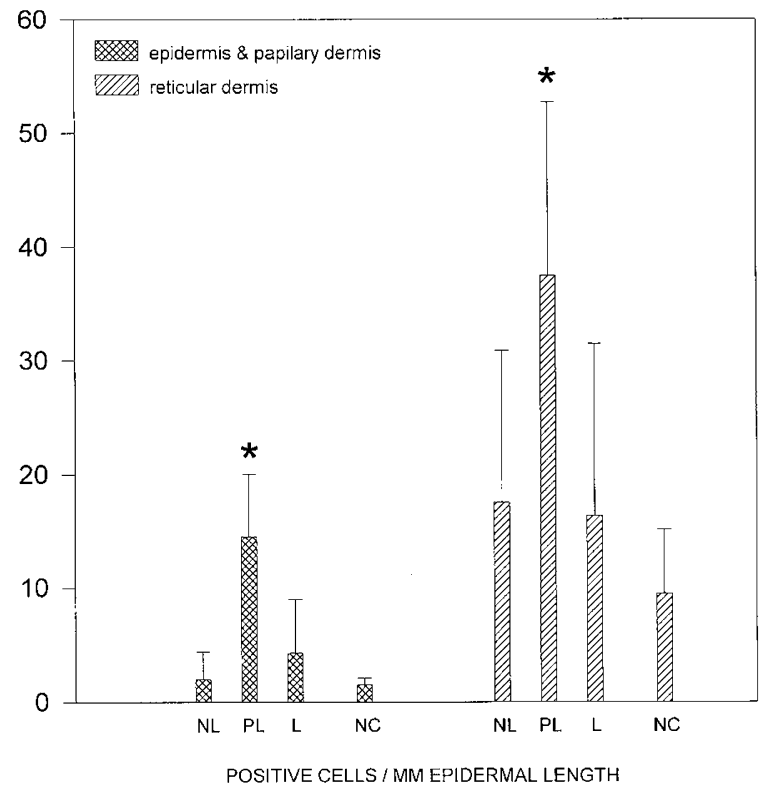

Figure 3.

Number of $\mathrm{CD}^{+} \mathrm{T}$ cells/mm epidermal length (mean $\pm \mathrm{SD}$ ) as calculated from CD8 single-label immunoreactivity. ${ }^{*} p<0.005$ versus NC skin.

tered at the epidermal/dermal junction at the site of melanocyte destruction (Fig. 2, C and D). To ascertain whether these $T$ cells had the ability to participate in cytotoxicity, we performed granzyme-B and perforin immunohistochemistry. Granzyme-B and perforin immunoreactivities were detected in PL skin exactly at the spots where $T$ cells interacted with melanocytes (see serial sections in Fig. 2, C to F) and were never observed in NL, L, or NC skin. To evaluate how many interacting $T$ cells were granzyme-B and perforin immunoreactive, cells immunoreactive for NKI-beteb/ CD8 or NKI-beteb/CD3 (double-label), perforin or granzyme-B (single-label) were counted in serial sections. Most of the T cells in apposition to melanocytes were $\mathrm{CD}^{+}$(average CD4 to CD8 ratio: 0.48). Most importantly, $66 \pm 14 \%$ (SD) of these interacting T cells expressed granzyme-B and $60 \pm 34 \%$ (SD) expressed perforin. Sections were also assessed for Fas and Fas-ligand immunoreactivity. Unfortunately, because the whole epidermis was immunoreactive for both molecules in all specimens, an accurate evaluation of the Fas and Fas-ligand expression by interacting $T$ cells and melanocytes at the epidermal/dermal junction was not possible (not shown).

Infiltrating $T$ cells were mostly of the leucocyte common antigen without exon (CD45RO) memory type and also expressed leucocyte function associated antigen-1 (LFA-1) (not shown). Figure 4 illustrates the number of CD25-expressing cells, which is highest in PL vitiligo skin ( $p<0.05$ versus NC skin). Increased numbers of activated $\mathrm{T}$ cells in $\mathrm{PL}$ skin were also found with CD3/HLA-DR double-label immunohistochemistry. In clusters of perivascularly located infiltrating cells, up to $70 \%$ of T cells were HLA-DR immuno-

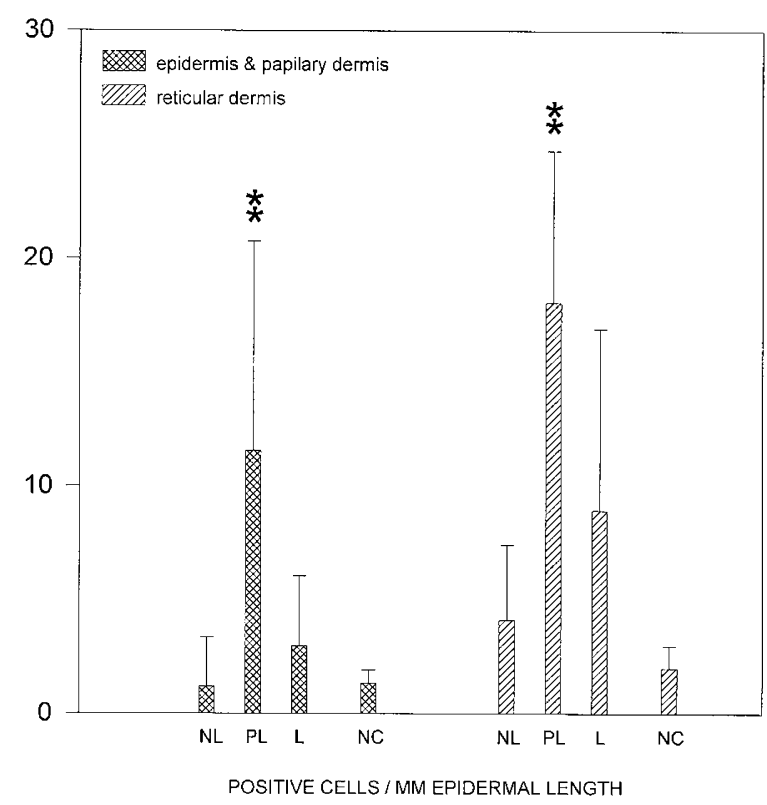

Figure 4.

Number of $\mathrm{CD}_{2} 5^{+}$cells $/ \mathrm{mm}$ epidermal length (mean $\pm \mathrm{SD}$ ) as calculated from CD25 single-label immunoreactivity. ${ }^{\star \star} p<0.05$ versus NC skin.

reactive whereas in $\mathrm{NC}, \mathrm{NL}$, and $\mathrm{L}$ skin, percentages varied from $10 \%$ to $40 \%$.

\section{B Cells and NK Cells}

No B cells or NK cells were detected in either vitiligo or control skin.

\section{Macrophages}

Increased numbers of macrophages, determined by a pan-macrophage marker, were found in skin from nine of ten patients compared with NC. More $\mathrm{CD} 8^{+}$cells were also found, particularly in the papillary dermis of $P L$ and $L$ skin. These data are summarized in Table 2. An example of the pattern in PL vitiligo skin compared with the pattern in NL skin is shown in Figure 5, A and B.

Moreover, CD1a/CD68 double-label immunhistochemistry revealed that a subset of epidermal Langerhans cells in vitiligo and NC skin sections expressed the CD68 antigen (not shown). Using a monoclonal antibody (mAb) to CD68 at a 40-fold-increased concentration, we observed that the antibody was reactive to all epidermal keratinocytes. This expression pattern was apparent in NC and NL vitiligo skin and was markedly reduced in $L$ vitiligo skin. An example is given in Figure $5 \mathrm{C}$, where a section spanning both $\mathrm{L}$ and NL skin (according to serial NKI-beteb immunoreactivity) is shown.

Melanocytes expressed CD36, another macrophage marker. The intensity of CD36 immunoreactivity of melanocytes varied, even for melanocytes within one section. NC as well as NL and PL vitiligo melano- 
Table 2. CD68 ${ }^{+}$Macrophages in Papilary Dermis of Vitiligo and Normal Control Skin

\begin{tabular}{ccccc}
\hline Patient Number & Control Skin & Nonlesional Skin & Perilesional Skin & Lesional Skin \\
\hline Normal Donor 1 & $1+$ & & & \\
Normal Donor 2 & $1+$ & & & \\
Normal Donor 3 & $1+$ & $1+$ & $1+$ & $2+$ \\
Vitiligo Donor 1 & & $1+$ & $2+$ & $1+$ \\
Vitiligo Donor 2 & & $1+$ & $3+$ & $2+$ \\
Vitiligo Donor 3 & & $1+$ & $2+$ & $2+$ \\
Vitiligo Donor 4 & & $1+$ & $2+$ & $2+$ \\
Vitiligo Donor 5 & & $1+$ & $2+$ & $1+$ \\
Vitiligo Donor 6 & & $1+$ & $1+$ & $1+$ \\
Vitiligo Donor 7 & & $1+$ & $2+$ & $1+$ \\
Vitiligo Donor 8 & & $1+$ & $2+$ & $1+$ \\
Vitiligo Donor 9 & & & \\
Vitiligo Donor 10 & & &
\end{tabular}

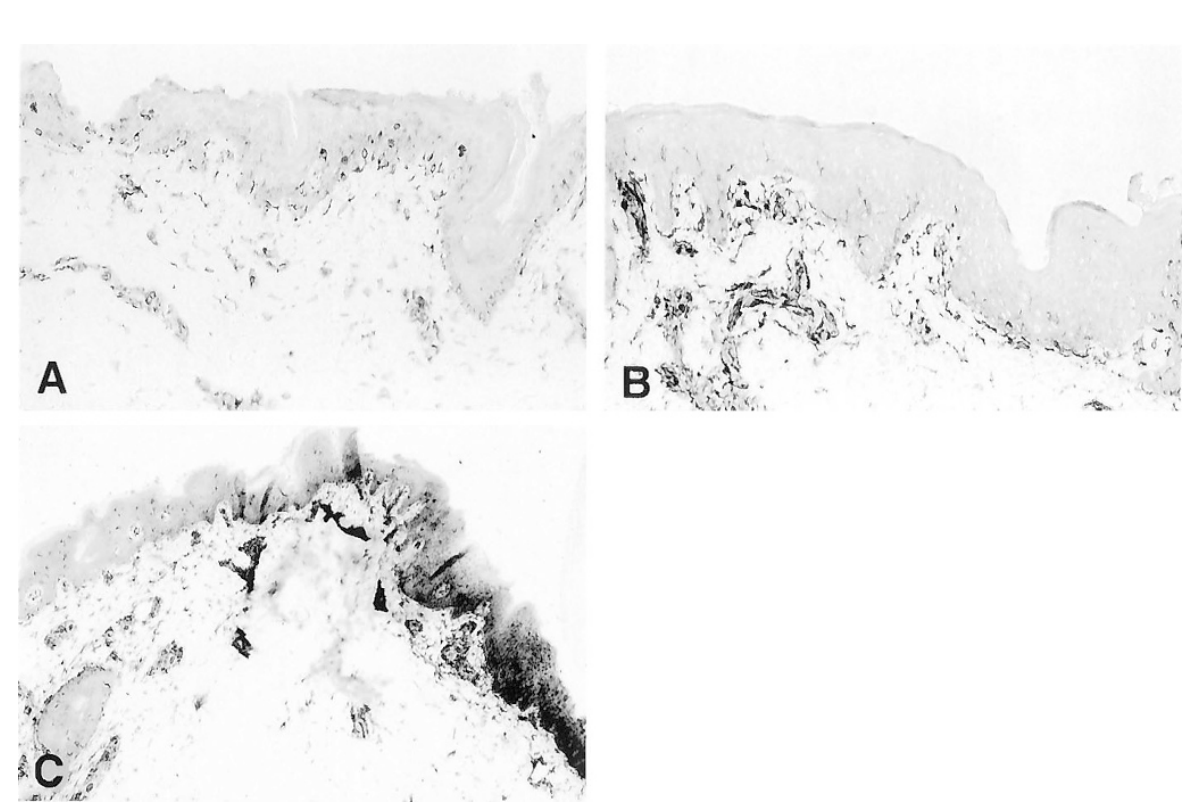

\section{Figure 5 .}

CD68 immunoenzymatic reactivity of $\mathrm{NL}(\mathrm{A})$ and $\mathrm{PL}(\mathrm{B})$ skin showing macrophage infiltrates. $\mathrm{C}$, Epidermal CD68 expression pattern in PL skin using high antibody concentration. Original magnifications: $A$ and $B, \times 66 ; C, \times 16$.

cytes were immunoreactive for CD36. Consequently, the total number of $\mathrm{CD}^{+}{ }^{+}$macrophages in each section was evaluated by subtracting the number of NKI-beteb/CD36 double-immunoreactive cells from the total number of CD36 ${ }^{+}$cells (Fig. 6). The observed differences were not statistically significant by the Mann-Whitney test.

\section{Langerhans Cells}

Considerable donor-to-donor variation was observed in epidermal Langerhans cell numbers both within generalized vitiligo patients and within the NC group. In one of the ten investigated patients, more Langerhans cells were detected in PL epidermis when compared with $L$ or NL skin. Decreased Langerhans cell numbers were observed in $L$ skin of seven patients, four of which were receiving ultraviolet-A (UVA) radiation therapy. Additionally, there was a tendency to- wards increased numbers of $\mathrm{CD}^{+}{ }^{+}$cells located along the basement membrane in PL and especially in $\mathrm{L}$ skin in all investigated patients. A representative example of this basal localization in PL skin is given in Figure 7.

\section{Keratinocytes}

Focal expression of HLA-DR, coinciding with the cellular infiltrates at the site of melanocyte loss, was detected in PL epidermis of eight of ten patients.

\section{Relevant Cell Adhesion Molecules: E-selectin and ICAM-1}

Vascular expression of E-selectin was found in all patient samples and in control specimens. When compared with NC tissue, E-selectin expression did not seem to be up-regulated, nor expressed in a 


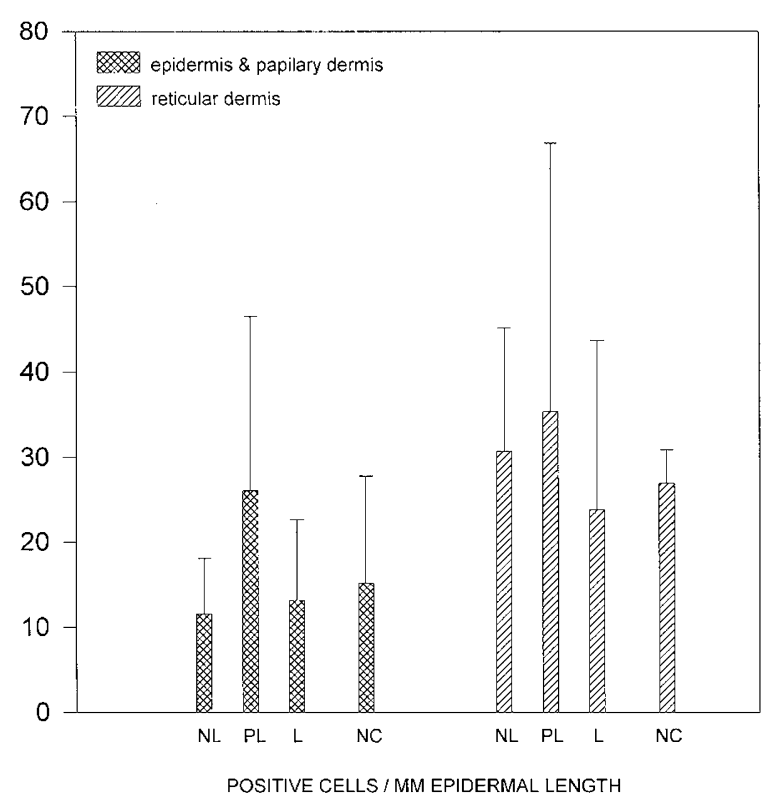

Figure 6.

Number of $\mathrm{CD} 36^{+}$cells/mm epidermal length (mean $\pm \mathrm{SD}$ ) as calculated from NKI-beteb/CD36 double-label immunoreactivity.

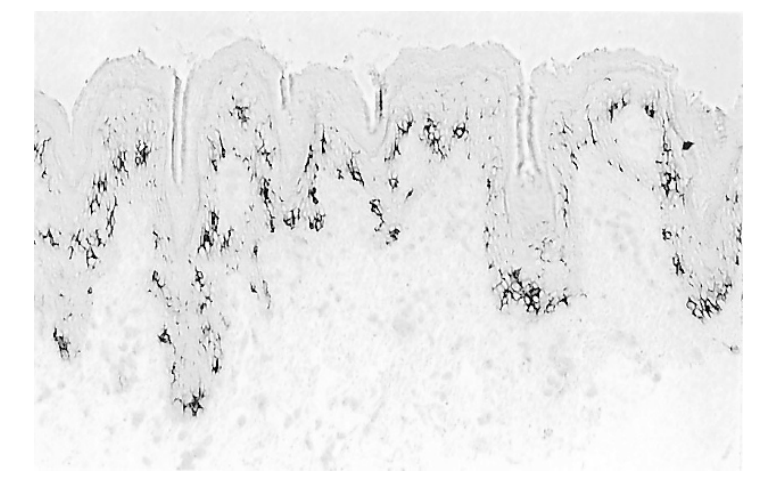

Figure 7.

Basal localization of CD1a-reactive Langerhans cells in the lesional (L) epidermis of a vitiligo donor. Original magnification, $\times 50$.

higher number of post-capillary venules in vitiligo skin. In contrast, the number of E-selectin-expressing post-capillary venules in psoriasis skin was significantly higher $(p<0.05)$ than in NC skin (Fig. 8). Importantly, the expression in vitiligo PL skin colocalized with the $\mathrm{T}$ cell infiltration.

ICAM-1 was detected on capillaries in the reticular and papillary dermis as well as on perivascularly located and scattered infiltrating cells. Focal epidermal expression was found in PL skin in eight of ten patients (Fig. 9), in contrast to NC or NL and $L$ vitiligo skin. The observed epidermal ICAM-1 expression coincided with the expression of HLA-DR according to immunohistochemistry of serial sections.

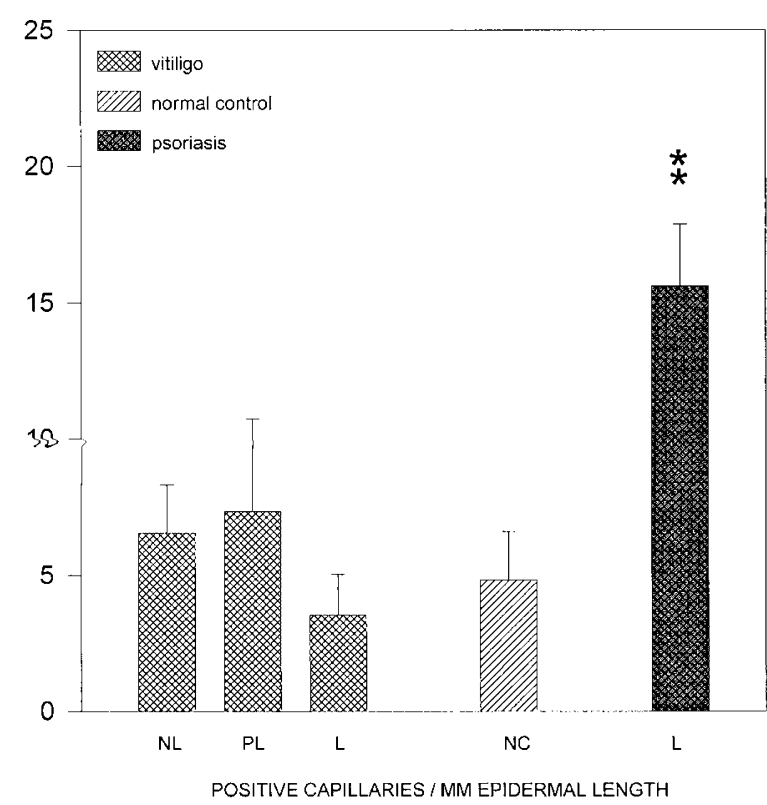

Figure 8.

Number of E-selectin ${ }^{+}$capillaries/mm epidermal length (mean \pm SD) as calculated from E-selectin single-label immunoreactivity. ${ }^{* \star} p<0.05$ versus NC skin.

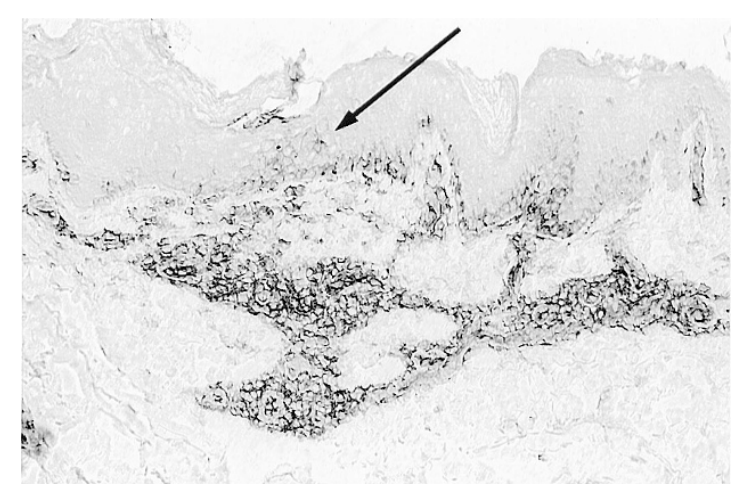

Figure 9.

ICAM-1 reactivity in PL skin of vitiligo donor. Note the focal epidermal expression (arrow). Original magnification, $\times 50$.

\section{Discussion}

This study, showing the consistent presence of immune infiltrates in PL skin of patients with the generalized type of vitiligo, confirms that an ongoing local immune response is associated with melanocyte destruction. The immune infiltrates are mainly composed of $T$ cells and macrophages. The number of infiltrating $\mathrm{T}$ cells, mostly consisting of $\mathrm{CD}^{+} / \mathrm{CD} 45 \mathrm{RO}^{+}$cells, was highest in the $\mathrm{PL}$ area. These $\mathrm{T}$ cells were frequently found in apposition to melanocytes and melanocyte remnants along the basement membrane, and were in an activated state indicated by their HLA-DR expressions. Moreover, some numbers of $\mathrm{CD}^{+} 5^{+} \mathrm{T}$ cells were increased in PL skin, indicating that ongoing $\mathrm{T}$ cell activation is involved in the pro- 
gressive depigmentation process. This assumption is supported by the observation that the majority of $\mathrm{T}$ cells detected in juxtaposition to PL melanocytes were perforin and granzyme-B immunoreactive. Because these effector molecules of lymphocyte granulemediated apoptosis (Froelich et al, 1998) were never observed in NL, L, or NC skin specimens, their apparent apposition to PL melanocytes is not coincidental. Interestingly, with respect to other pathways for CTLinduced apoptosis, such as Fas and Fas-ligand (Nagata, 1997), our unpublished in vitro observations clearly indicate that melanocytes are insensitive to Fas-ligand-mediated cell death (van den Wijngaard et al, unpublished observations). This is compatible with the report that despite melanocytic expression of Fas, Fas-ligand-mediated apoptosis cannot be induced in these cells (Rivoltini et al, 1998).

Furthermore, the prevalence of $\mathrm{CD}^{+} \mathrm{T}$ cells over $\mathrm{CD}^{+}{ }^{+} \mathrm{T}$ cells seems to be a prominent feature in generalized vitiligo. Such an imbalance in CD4 to CD8 ratios was also reported in a study on the Smyth line chicken animal model for vitiligo, where $\mathrm{CD} 8^{+} \mathrm{T}$ cells prevail after the onset of the depigmentation process (Erf et al, 1995). Furthermore, the presence of activated $T$ cells in generalized vitiligo may be due to the preferential migration of skin-homing $\mathrm{CLA}^{+} \mathrm{T}$ cells near target melanocytes. Our study demonstrated that the relative number of $\mathrm{CLA}^{+}$cells in $\mathrm{PL}$ infiltrates is comparable to the normal situation and other inflammatory skin diseases such as contact dermatitis (de Boer et al, 1994b). The absence of a relative increase in $\mathrm{CLA}^{+}$cells is compatible with the normal number of E-selectin-expressing post-capillary venules, because $\mathrm{E}$-selectin on vascular endothelium is the natural ligand for $\mathrm{CLA}^{+}$immune infiltrating cells (de Boer et al, 1994a). Interestingly, E-selectin expression colocalized with the perivascular $\mathrm{T}$ cell infiltration in $\mathrm{PL}$ skin and the absolute number of $\mathrm{CLA}^{+} \mathrm{T}$ cells was higher in PL vitiligo skin than in NL skin. Importantly, $\mathrm{CLA}^{+} \mathrm{T}$ cells were frequently detected as clusters at the epidermal/dermal junction where melanocytes are in the process of disappearing. In psoriasis and contact dermatitis, however, such $\mathrm{CLA}^{+} \mathrm{T}$ cells are incidentally observed in apposition to melanocytes and melanocyte destruction does not occur in these inflammatory dermatoses. Therefore, it is likely that skin-homing $\mathrm{T}$ cells in vitiligo PL skin are specifically involved in melanocyte destruction.

In conjunction with the $\mathrm{T}$ cell infiltrates, we also observed HLA-DR expression by PL melanocytes. In this respect, it was previously suggested that melanocytic HLA-DR expression may contribute to the destruction of melanocytes in pigmentary disorders. This assumption was based upon in vitro experiments where it was demonstrated that melanocytes can process antigen and present its antigenic peptides to HLA-DR-restricted T cell clones (Le Poole et al, 1993a). Because these clones were able to respond both in a proliferative and in a cytotoxic fashion, it was concluded that HLA-DR-expressing melanocytes can contribute to the local immune response in vivo by presenting antigen, and simultaneously, become tar- gets for cytotoxic T cells. Besides focal expression of HLA-DR, concomitant expression of ICAM-1 in the epidermis indicates that this costimulatory molecule may render melanocytes susceptible to recruited antigen-specific $T$ cells.

In addition to $T$ cell infiltrates, we also demonstrated macrophage infiltrates in vitiligenous skin. Macrophage infiltrates were characterized using the panmacrophage marker CD68 and the macrophage subset marker CD36. Macrophage CD36 expression was investigated because it has been reported that CD36 promotes efficient phagocytosis of apoptotic cells (Ren et al, 1995). Additionally, cytotoxic T cells kill their target cells via the induction of apoptosis (Froelich et al, 1998; Nagata, 1997). In this study, a significant increase in $\mathrm{CD}^{+}{ }^{+}$cells was not observed at the site of melanocyte disappearance. However, in nine of ten patients, increased numbers of $\mathrm{CD}^{+} 8^{+}$macrophages were present in PL skin. In addition to the possibility that infiltrating macrophages are involved in clearing apoptotic cells (Savill, 1997), a direct involvement of macrophages in melanocyte killing, probably via the nitric oxide pathway (Dimmeler and Zeiher, 1997), cannot be ruled out. Using 3-morpholino-syndonimine $(\mathrm{SIN}-1)$ as a nitric oxide donor, it has been observed that nitric oxide induces detachment and apoptosis of melanocytes cultured on fibronectin-coated plates $(\mathrm{K}$. Ivanova, Institute of Aerospace Medicine, Germany, personal communication, 1998).

When investigating the distribution of the panmacrophage marker CD68, double-label immunohistochemistry showed some Langerhans cells but all melanocytes to be CD68 ${ }^{+}$. The expression of CD68 by Langerhans cells is in agreement with earlier reports (Petzelbauer et al, 1993). Because CD68 and also CD36 are phagocytosis-related markers, their expressions on melanocytes are compatible with the fact that pigment cells have a phagocytic capacity (Le Poole et al, 1993c). Furthermore, CD36 expression on melanocytic cells has been previously reported (De Panfilis et al, 1993; Foster, 1993). In addition to epidermal expression of macrophage markers by melanocytes and Langerhans cells, we observed that the whole epidermis was also immunoreactive for CD68 when using high antibody concentrations. This expression was high in skin sections containing melanocytes (both in $\mathrm{NC}$ and NL vitiligo skin) and reduced when melanocytes were absent. The latter finding was consistent among patients and comparable to findings reported for inflammatory vitiligo (Le Poole et al, 1996). The markedly reduced expression in melanocyte-depleted L skin suggests that CD68 expression in control and noninvolved vitiligo epidermis may be due to melanocytes. This implies that the absence of intense CD68 immunoreactivity is a feature of $L$ skin in all hypopigmentary disorders. We observed a similar immunohistochemical pattern in each of three patients with the congenital hypopigmentary disorder piebaldism (not shown).

Despite the expression of different immunologic markers by epidermal cells, the main focus of this study is the interaction of locally recruited immuno- 
competent cells in relation to vitiligo pathology. In this respect, another important cell is the epidermal Langerhans cell. We observed a decreased number of lesional Langerhans cells in seven of ten patients. Four of these patients were receiving UVA radiation therapy and it has been reported that UVA therapy leads to a decreased presence of Langerhans cells in $L$ vitiligo skin (Kao and Yu, 1990; Westerhof et al, 1986). Surprisingly, the tendency toward a more basal location of Langerhans cells seen in PL and $L$ skin was independent of UVA radiation exposure; this is in agreement with the results reported in literature (Birbeck et al, 1961; Westerhof et al, 1986).

The presence of in situ immune infiltrates and their interactions with epidermal melanocytes are major features in vitiligo pathology. However, the absolute number of infiltrating cells in PL skin is limited, compared with numbers found in other inflammatory skin diseases. This underscores the importance of careful selection of biopsy material because when PL biopsies do not span both $L$ and NL skin of an expanding lesion, it may be falsely concluded that immune infiltrates are not involved in vitiligo pathogenesis. The presence of limited numbers of infiltrating cells may be attributed to 1) the low number and dispersed localization of target cells (melanocytes), 2) the recirculatation of $\mathrm{T}$ cells after delivering their lethal hits, or 3 ) infiltrating $T$ cells entering activation-induced apoptosis (Akbar and Salmon, 1997). The latter possibility also underscores the importance of infiltrating macrophages because they efficiently clear apoptotic cells (Savill, 1997).

Recently it was demonstrated that CLA-expressing CTL, specific for the melanocyte differentiation antigen Melan-A, can be isolated from peripheral blood of vitiligo patients (Ogg et al, 1998). Importantly, bloodderived Melan-A-specific CTL derived from a NC donor did not express CLA. Moreover, in cooperation with these investigators, we found Melan-A-specific, $\mathrm{CLA}^{+} / \mathrm{CD}^{+} \mathrm{T}$ cells in cell lines derived from PL vitiligo skin biopsies (Kalinska et al, unpublished observations). Together with the in situ data presented in this report, this proves that CLA expression is an essential feature for effective autoreactive response by melanocyte-specific $\mathrm{T}$ cells in PL skin. Because the present study clearly shows the increased in situ presence of activated, granzyme-B and perforin expressing $\mathrm{CLA}^{+} / \mathrm{CD}^{+} \mathrm{T}$ cells, and their apposition to the disappearing melanocytes at the PL site, we conclude that in vivo destruction of melanocytes in vitiligo is primarily mediated by these skin-homing $\mathrm{CD}^{+} \mathrm{T}$ cells.

\section{Materials and Methods}

\section{Tissue Specimens}

Ten patients diagnosed with the generalized type of vitiligo were included in this study. Their demographic data are given in Table 3. All patients had progressive disease, evaluated by the patients own observations. Four millimeter punch biopsies were taken from expanding lesions, snap frozen in liquid nitrogen, and stored at $-80^{\circ} \mathrm{C}$. PL biopsies were taken after carefully marking the pigmented side bordering the vitiligenous spot with ink. This facilitated the precise cutting of sections spanning both $L$ and NL skin. PL skin was obtained from only one of the ten investigated patients. NL and L skin was taken 2 to 5 centimeters away from the PL area. Adult breast skin and abdominal skin specimens were obtained from plastic surgery tissue for NC $(n=4)$. Additional controls were obtained from the inside border of active psoriasis lesions $(n=4)$ and patch-tested (72 hours) delayed type hypersensitivity reactive skin from contact dermatitis patients $(n=4)$. Six micron cryostat sections were cut, air-dried, fixed in $4^{\circ} \mathrm{C}$ acetone, and stored at $-20^{\circ} \mathrm{C}$ until use.

\section{Single-Label Immunohistochemistry}

CD codes, specificities, sources, and working dilutions for all $\mathrm{mAb}$ are given in Table 4. Immunohistochemistry was performed according to the streptavidin-biotin immunoperoxidase method described previously (Hsu et al, 1981). Briefly, sections were first incubated in PBS with $0.1 \%$ sodium azide and $0.3 \%$ hydrogen peroxide (Merck, Darmstadt, Germany) to quench intracellular peroxidases. After incu-

Table 3. Demographic Data on the Generalized Type of Vitiligo Patients Used in This Study

\begin{tabular}{|c|c|c|c|c|c|c|}
\hline $\begin{array}{l}\text { Patient } \\
\text { Number }\end{array}$ & Sex & Age & $\begin{array}{l}\text { Biopsy } \\
\text { Taken } \\
\text { from }\end{array}$ & $\begin{array}{c}\text { Duration of } \\
\text { Vitiligo }\end{array}$ & $\begin{array}{l}\text { Course of } \\
\text { Lesion }\end{array}$ & Medication \\
\hline $1^{*}$ & M & 54 & arm & 9 years & progressive & none \\
\hline $2^{*}$ & $\mathrm{~F}$ & 49 & $\operatorname{leg}$ & 10 years & progressive & cellocane (blood pressure) \\
\hline $3^{*}$ & $\mathrm{M}$ & 43 & arm & 10 years & progressive & none \\
\hline 4 & M & 35 & back & 30 years & progressive & tetracyclin (acne) \\
\hline 5 & M & 38 & hip & 1 year & progressive & none \\
\hline $6^{\star}$ & $\mathrm{F}$ & 33 & hip & 7 years & progressive & diprosone \\
\hline 7 & $\mathrm{~F}$ & 40 & arm & 1 year & progressive & none \\
\hline 8 & $\mathrm{M}$ & 48 & arm & 4 months & progressive & none \\
\hline 9 & $\mathrm{~F}$ & 26 & foot & 10 years & progressive & none \\
\hline 10 & M & 35 & Hip & 5 years & progressive & none \\
\hline
\end{tabular}

* Patient receiving psoralen/UVA (PUVA) treatment when biopsies were taken. 
Table 4. CD Code, Specificity, Source, and Working Dilution of All Monoclonal Antibodies Used in This Investigation

\begin{tabular}{|c|c|c|c|c|}
\hline Monoclonal & CD code & Specificity & Source & Dilution \\
\hline OKT-6 & CD1a & Langerhans cells & Ortho $^{1}$ & $1: 50$ \\
\hline OKT-6*FITC & CD1a & Langerhans cells & Ortho & $1: 100$ \\
\hline Leu 4 & CD3 & all T cells & $B \& D^{2}$ & $1: 20$ \\
\hline Leu 4 *FITC & CD3 & all T cells & $B \& D$ & $1: 200$ \\
\hline Leu3a & CD4 & helper T cells, subpopulation monocytes and macrophages & $B \& D$ & $1: 20$ \\
\hline T8 & CD8 & suppressor and cytotoxic T cells & Dako $^{3}$ & $1: 200$ \\
\hline \multirow[t]{2}{*}{ T8*FITC } & CD8 & suppressor and cytotoxic T cells & Dako & $1: 50$ \\
\hline & CD11a & majority lymphoid and myeloid cells (LFA-1) & ATCC $^{4}$ & $1: 10$ \\
\hline HD37 & CD19 & all $B$ cells & Dako & $1: 100$ \\
\hline Leu14 & CD22 & precursor and mature B cells & $B \& D$ & $1: 1$ \\
\hline Tu69 & CD25 & $\begin{array}{l}\text { activated T and B cells } \\
\text { activated macrophages (II-2 receptor) }\end{array}$ & Biotest $^{5}$ & $1: 100$ \\
\hline OKM 5 & CD36 & subpop. monocytes and macrophages & Ortho & $1: 50$ \\
\hline UCHL1 & CD45R0 & memory T cells & Dako & $1: 25$ \\
\hline Leu18 & CD45RA & virgin T cells & $B \& D$ & $1: 25$ \\
\hline RR1 & CD54 & ICAM-1 (broad tissue distribution) & Dr. T. Springer 6 & $1: 1000$ \\
\hline Leu7 & CD57 & subpopulation of NK cells & $B \& D$ & $1: 20$ \\
\hline BBIG-E4 & CD62E & activated endothelial cells & $R \& D^{7}$ & $1: 100$ \\
\hline KP1 & CD68 & all macrophages & Dako & $1: 2000$ \\
\hline UB2 & CD95 & Fas (broad distribution) & Immunotech ${ }^{8}$ & $1: 100$ \\
\hline 33 & CD95-L & Fas-Ligand (broad distribution) & Transduction $^{9}$ & $1: 100$ \\
\hline Delta G91 & perforin & activated CTL and NK cells & Endogen ${ }^{10}$ & 0.07639 \\
\hline GrB-7 & Granzyme B & activated CTL and NK cells & Monosan ${ }^{11}$ & 0.07639 \\
\hline L243 & HLA-DR & MHC-II (HLA-DR specificity) & $B \& D$ & $1: 50$ \\
\hline L243*FITC & HLA-DR & MHC-II (HLA-DR specificity) & $B \& D$ & $1: 50$ \\
\hline HECA-452 & CLA & cutaneous lymphocyte-associated antigen & Dr S. Hardy ${ }^{12}$ & $1: 50$ \\
\hline NKI-beteb & GP-100 & melanocyte differentiation antigen & Sanbio $^{11}$ & $1: 40$ \\
\hline
\end{tabular}

1, Ortho Diagnostics, Raritan, New Jersey; ${ }^{2}$, Becton \& Dickinson, Mountain View, California; ${ }^{3}$, Dakopatts, Glostrupp, Denmark; ${ }^{4}$, American Type Culture Collection, Manassas, Virginia; ${ }^{5}$, Biotest, Dreieich, Germany; ${ }^{6}$, Dr T. Springer, Harvard Medical School, Boston, Massachusetts; ${ }^{7}$, R\&D Systems, Minneapolis, Minnesota; ${ }^{8}$, Immunotech, Marseille, France; ${ }^{9}$, Transduction Laboratories, Lexington, Kentucky; ${ }^{10}$, Endogen, Woburn, Massachusetts; ${ }^{11}$, Monosan/Sanbio BV, Uden, The Netherlands; ${ }^{2}$, Dr S. Hardy, UCLA Tissue Typing Laboratory, Los Angeles, California.

bation with $10 \%$ normal goat serum (Dakopatts, Glostrupp, Denmark), sections were incubated with the primary mAb. Sections were then incubated with biotinylated rabbit anti-mouse serum (1:200, Dakopatts), followed by steptavidin ABC-horse radish peroxidase complex (Dakopatts). Peroxidase activity was visualized with 3-amino-9-ethyl carbazole (Sigma Chemical Company, St Louis, Missouri). To ensure specificity, isotype-matched irrelevant mAb with specificity to Aspergillus niger glucose oxidase (Dakopatts) was used as a negative control in place of primary antibodies. For granzyme-B immunohistochemistry, sections were pretreated by non-enzymatic antigen retrieval as previously described (Wever et al, 1997). Briefly, preparations were subjected to formalin fixation (4\% buffered formalin, 10 minutes) and subsequent boiling in sodium citrate buffer $(10 \mathrm{~mm}, \mathrm{pH}$ 6.0, 10 minutes). After this step, sections were processed as described above.

\section{Double-Label Immunohistochemistry}

These combinations of antibodies were used in double-label immunohistochemical procedures: CD3*FITC/CD8, CD3*FITC/HLA-DR, CD3*FITC/ HECA-452, CD8*FITC/HECA-452, CD1a*FITC/CD68,
CD8*FITC/NKI-beteb, HLA-DR*FITC/NKI-beteb, NKIbeteb/CD68, and NKI-beteb/CD36.

Two methods of double-label immunohistochemistry were used (van der Loos et al, 1993):

1. Unlabeled mAb was used first, followed by incubation with alkaline phosphatase-labeled goat antimouse serum (1:20, Dakopatts). Subsequently, sections were incubated with the second, FITClabeled, mAb, followed by incubation with rabbit anti-FITC (1:1000, Dakopatts) and peroxidaselabeled swine anti-rabbit (1:100, Dakopatts). Alkaline phosphatase activity was visualized with Fast Blue BB (Sigma Chemical Company) and peroxidase activity was visualized with 3-amino-9-ethyl carbazole.

2. For NKI-beteb/CD68 and NKI-beteb/CD36 doublelabel immunohistochemistry, sections were incubated with a mixture of the two mAb of different isotypes (NKI-beteb: IgG2b, CD68 and CD36: IgG1). Two subclass-specific polyclonal antibodies were mixed and incubated with the sections; alkaline phosphatase-labeled goat anti-mouse IgG1 (1:10 dilution) and peroxidase-labeled goat antimouse IgG2b (1:20 dilution) (Southern Biotechnology, Birmingham, Alabama). Enzyme activities 
were visualized with Fast Blue BB and 3-amino-9ethyl carbazole.

\section{Evaluation of Immunohistochemistry}

Because melanocytes are located in the basal layer of the epidermis, $T$ cells in juxtaposition to melanocytes are located in the epidermis and in the papillary dermis. Therefore, in this investigation, the epidermis and the papillary dermis were evaluated as one compartment and the number of immunoreactive cells was quantified per millimeter of epidermis.

The relative distribution of $\mathrm{CD}^{+}{ }^{+}$and $\mathrm{CD} 8^{+} \mathrm{T}$ cells in the infiltrates was evaluated using CD3/CD8 double-label immunohistochemistry. $\mathrm{CD}^{+} \mathrm{T}$ cells were counted as the total number of $\mathrm{CD}^{+}$cells minus the number of CD3/CD8 double-immunoreactive cells. For CD68 and CD1a, immunoreactive cell numbers were too high for accurate counting. Immunoreactive cells were quantified on a scale from $1+$ to $3+$. Percentages of HECA-452/CD3 and HLA-DR/CD3 double-immunoreactive cells were scored by evaluating clusters of infiltrating cells in five separate fields and calculating the average percentage, and also by counting disperse double-immunoreactive cells. Evaluations were made by two independent observers. Differences between NC and patient results were tested for statistical significance using the nonparametric Mann-Whitney test and were assessed as significant for $p<0.05$.

\section{References}

Abdel-Naser MB, Kruger-Krasagakes S, Krasagakis K, Gollnick H, Abdel-Fattah A, and Orfanos CE (1994). Further evidence for involvement of both cell mediated and humoral immunity in generalized vitiligo. Pigment Cell Res 7:1-8.

Akbar AN and Salmon M (1997). Cellular environments and apoptosis: Tissue microenvironments control activated T-cell death. Immunol Today 18:72-76.

Anichini A, Maccalli C, Mortarini R, Salvi S, Mazzocchi A, Squarcina P, Herlyn M, and Parmiani G (1993). Melanoma cells and normal melanocytes share antigens recognized by HLA- A2-restricted cytotoxic T cell clones from melanoma patients. J Exp Med 177:989-998.

Badri AM, Todd PM, Garioch JJ, Gudgeon JE, Stewart DG, and Goudie RB (1993). An immunohistological study of cutaneous lymphocytes in vitiligo. J Pathol 170:149-155.

Berd D, Mastrangelo MJ, Lattime E, Sato T, and Maguire HC Jr (1996). Melanoma and vitiligo: Immunology's Grecian urn. Cancer Immunol Immunother 42:263-267.

Birbeck MS, Breathnach AS, and Everall JD (1961). An electron microscope study of basal melanocytes and highlevel clear cells (Langerhans cells) in vitiligo. J Invest Dermatol 37:51-64.

Coulie PG, Brichard V, Van Pel A, Wolfel T, Schneider J, Traversari C, Mattei S, De Plaen E, Lurquin C, Szikora JP, Renauld JC, and Boon T (1994). A new gene coding for a differentiation antigen recognized by autologous cytolytic $T$ lymphocytes on HLA-A2 melanomas. J Exp Med 180:35-42.

de Boer OJ, Horst E, Pals ST, Bos JD, and Das PK (1994a). Functional evidence that the HECA-452 antigen is involved in the adhesion of human neutrophils and lymphocytes to tumour necrosis factor-alpha-stimulated endothelial cells. Immunology 81:359-365.

de Boer OJ, Verhagen CE, Visser A, Bos JD, and Das PK (1994b). Cellular interactions and adhesion molecules in psoriatic skin. Acta Derm Venereol Suppl 186:15-18.

De Panfilis G, Manara GC, Ferrari C, Torresani C, Lonati A, Pasolini G, and Rowden G (1993). Melanocytes freshly isolated from normal human skin express the cell membrane receptor for the adhesive glycoprotein thrombospondin. $\mathrm{Br} \mathrm{J}$ Dermatol 129:131-137.

Dimmeler S and Zeiher AM (1997). Nitric oxide and apoptosis: Another paradigm for the double-edged role of nitric oxide. Nitric Oxide 1:275-281.

Dunbar PR, Chen JL, Chao D, Rust N, Teisserenc H, Ogg GS, Romero P, Weynants P, and Cerundolo V (1999). Cutting edge: Rapid cloning of tumor-specific CTL suitable for adoptive immunotherapy of melanoma. J Immunol 162:69596962.

Erf GF, Trejo-Skalli AV, and Smyth JR Jr (1995). T cells in regenerating feathers of Smyth line chickens with vitiligo. Clin Immunol Immunopathol 76:120-126.

Foster CA (1993). Heterogeneity among CD36 $^{+}$cells in normal and diseased human skin. In: Nickoloff BJ, editor. Dermal Immune system. Boca Raton: CRC press, 245-267.

Froelich CJ, Dixit VM, and Yang X (1998). Lymphocyte granule-mediated apoptosis: Matters of viral mimicry and deadly proteases. Immunol Today 19:30-36.

Harning R, Cui J, and Bystryn JC (1991). Relation between the incidence and level of pigment cell antibodies and disease activity in vitiligo. J Invest Dermatol 97:1078-1080.

Honda Y, Okubo Y, and Koga M (1997). Relationship between levels of soluble interleukin-2 receptors and the types and activity of vitiligo. J Dermatol 24:561-563.

Hsu SM, Raine L, and Fanger H (1981). Use of avidin-biotinperoxidase complex $(A B C)$ in immunoperoxidase techniques: A comparison between $A B C$ and unlabeled antibody (PAP) procedures. J Histochem Cytochem 29:577-580.

Kao CH and Yu HS (1990). Depletion and repopulation of Langerhans cells in nonsegmental type vitiligo. J Dermatol 17:287-296.

Keystone EC, Snow KM, Bombardier C, Chang CH, Nelson DL, and Rubin LA (1988). Elevated soluble interleukin-2 receptor levels in the sera and synovial fluids of patients with rheumatoid arthritis. Arthritis Rheum 31:844-849.

Kovacs SO (1998). Vitiligo. J Am Acad Dermatol 38:647-666.

Le Poole IC, Mutis T, van den Wijngaard RM, Westerhof W, Ottenhoff T, de Vries RR, and Das PK (1993a). A novel, antigen-presenting function of melanocytes and its possible relationship to hypopigmentary disorders. J Immunol 151: 7284-7292.

Le Poole IC, van den Wijngaard RM, Westerhof W, and Das PK (1996). Presence of T cells and macrophages in inflammatory vitiligo skin parallels melanocyte disappearance. Am J Pathol 148:1219-1228.

Le Poole IC, van den Wijngaard RM, Westerhof W, Dutrieux RP, and Das PK (1993b). Presence or absence of melanocytes in vitiligo lesions: An immunohistochemical investigation. J Invest Dermatol 100:816-822. 
Le Poole IC, van den Wijngaard RM, Westerhof W, Verkruisen RP, Dutrieux RP, Dingemans KP, and Das PK (1993c). Phagocytosis by normal human melanocytes in vitro. Exp Cell Res 205:388-395.

Lerner AB (1971). On the etiology of vitiligo and gray hair. Am J Med 51:141-147.

Nagata S (1997). Apoptosis by death factor. Cell 88:355-365.

Norris DA, Horikawa T, and Morelli JG (1994). Melanocyte destruction and repopulation in vitiligo. Pigment Cell Res 7:193-203.

Ogg GS, Rod Dunbar P, Romero P, Chen JL, and Cerundolo $V$ (1998). High frequency of skin-homing melanocyte-specific cytotoxic T lymphocytes in autoimmune vitiligo. J Exp Med 188:1203-1208.

Petzelbauer P, Fodinger D, Rappersberger K, Volc-Platzer B, and Wolff K (1993). CD68 positive epidermal dendritic cells. J Invest Dermatol 101:256-261.

Picker LJ, Michie SA, Rott LS, and Butcher EC (1990). A unique phenotype of skin-associated lymphocytes in humans. Preferential expression of the HECA-452 epitope by benign and malignant T cells at cutaneous sites. Am J Pathol 136:1053-1068.

Ren Y, Silverstein RL, Allen J, and Savill J (1995). CD36 gene transfer confers capacity for phagocytosis of cells undergoing apoptosis. J Exp Med 181:1857-1862.

Rivoltini L, Radrizzani M, Accornero P, Squarcina P, Chiodoni C, Mazzocchi A, Castelli C, Tarsini P, Viggiano V, Belli F, Colombo MP, and Parmiani G (1998). Human melanomareactive $\mathrm{CD} 4+$ and $\mathrm{CD} 8+\mathrm{CTL}$ clones resist Fas ligandinduced apoptosis and use Fas/Fas ligand-independent mechanisms for tumor killing. J Immunol 161:1220-1230.
Rosenberg SA (1997). Cancer vaccines based on the identification of genes encoding cancer regression antigens. Immunol Today 18:175-182.

Savill J (1997). Recognition and phagocytosis of cells undergoing apoptosis. Brit Med Bull 53:491-508.

van der Loos CM, Becker AE, and van den Oord JJ (1993). Practical suggestions for successful immunoenzyme doublestaining immunoenzyme. Histochem J 25:1-13.

Westerhof W, Groot I, Krieg SR, Bos JD, and Cormane RH (1986). Langerhans' cell population studies with OKT6 and HLA-DR monoclonal antibodies in vitiligo patients treated with oral phenylalanine loading and UVA irradiation. Acta Derm Venereol 66:259-262.

Wever PC, Mulder JB, Weening JJ, and ten Berge IJ (1997). Immunocytochemical detection of granzymes A and B in peripheral blood lymphocytes from healthy individuals after non-enzymatic antigen retrieval. J Histochem Cytochem 45: 467-469.

Wolf RE and Brelsford WG (1988). Soluble interleukin-2 receptors in systemic lupus erythematosus. Arthritis Rheum 31:729-735.

Zeff RA, Freitag A, Grin CM, and Grant-Kels JM (1997). The immune response in halo nevi. J Am Acad Dermatol 37:620 624. 